\title{
Investigation of Volatile Compounds from the Concrete of Jasminum auriculatum Flowers
}

\author{
P. Ranchana*, M. Ganga, M. Jawaharlal and M. Kannan \\ Department of Floriculture and Landscaping, HC\& RI, TNAU, \\ Coimbatore- 3, Tamil Nadu, India \\ *Corresponding author
}

A B S T R A C T

\section{Keywords}

Jasmine, Jasminum auriculatum,

Concrete, Volatile compounds, GC-MS.

Article Info

Accepted:

12 September 2017

Available Online:

10 November 2017
Essential oils are plant-based volatile oils with strong aromatic components (Younis et al., 2008). Jasmine fragrance gives a feeling of optimism, confidence and euphoria and is helpful against depression, nervous exhaustion and stress related conditions. Three species of jasmine viz., Jasminum sambac, Jasminum auriculatum and Jasminum grandiflorum is cultivated in a commercial scale (Rimando, 2003; Green and Miller, 2009). Among these, the flowers of Jasminum auriculatum are white, sweet scented, borne in pubescent compound many flowered cymes. In this study, Jasminum auriculatum concrete extraction was carried out by solvent extraction with hexane for three varieties viz., CO-1 mullai, CO2 mullai and Parimullai which is cultivated in South India. The chemical composition of the concrete was analysed by gas chromatography- mass spectrometry (GC-MS). The results showed that percentage yield of concrete were in the range of 0.28 to $0.36 \%$ per cent. The major chemical components detected were 17-Pentatriacontene; Octadecane, 3ethyl-5-(2-ethylbutyl); 11-Pentanol, 4-methyl-2-propyl-. The result of this study showed that the GC-MS study is selective, rapid and efficient for the identification of volatile components and composition variations.

\section{Introduction}

Jasmine is a highly domesticated ornamental plant grown mainly for its fragrant flowers. Three species of jasmine viz., Jasminum sambac, Jasminum auriculatum and Jasminum grandiflorum is cultivated in a commercial scale (Rimando, 2003; Green and Miller, 2009). Flowers and buds are used for making garlands, bouquets, veni, used for decorating hair of women and for religious offerings. Jasmine oil is regarded as unique, as it blends well with other floral extracts. It is highly valued throughout the world for its high grade perfumes, which is used in soap and cosmetic industries and in flavouring mouth wash liquids.
Jasminum auriculatum is a shrubby plant having shiny leaves with auricles. Flowers are white, sweet scented, borne in compound cymes; Corolla lobes are elliptic; carpels are solitary and globose. Fruits black. Flowers used for production of perfumes (Arumugam et al., 2002). Three varieties of Jasminum auriculatum viz., CO-1 mullai, CO-2 mullai and Parimullai are cultivated in South India.

Concrete is extracted from the fully blossomed flower. All the fragrance compounds are not easily released from the fibrous materials of the flowers. It is advisable to do the extraction of concrete 
when the major fragrance compounds are started releasing vigorously i.e. when sudden increase in fragrance takes place from the flower. A non-polar solvent such as Hexane is used to "wash" the aromatic compounds out of the flowers. After the hexane is evaporated a waxy, semisolid substance known as a "concrete" is left.

Gas Chromatography-Mass Spectrometry (GCMS) is a process that integrated the features of gas chromatography and mass spectrometry to improve efficacy of qualitative and quantitative analysis within a test sample. The gas chromatograph applies which depend on the column (type, material, length, diameter, film thickness) as well as the phase properties. The mass spectrometer does this by breaking each molecule into ionized fragments and detecting these fragments using their mass to charge ratio (Bramer, 1998). Applications of GC-MS include drug detection, plasma detection, environmental analysis, explosives investigation, and identification of unknown samples. Additionally, it can identify trace elements in materials that were previously thought to have disintegrated beyond identification. The purpose of this study was to identify the volatile compounds released from three varieties of Jasminum auriculatum viz., CO-1 mullai, CO-2 mullai and Parimullai.

\section{Materials and Methods}

\section{Flower preparations}

Freshly opened blossoms were collected every day before 9.30 a.m., weighed and subjected to extraction.

\section{Extraction method- Solvent extraction}

For extraction of concrete, the flowers were harvested when fully opened before 9.30 AM. Concrete content of flowers was analyzed by solvent extraction method (ASTA, 1960) with food grade hexane, averaged and expressed in per cent of concrete recovery. A sample of fifty gram was taken in the glass column of Soxhlet apparatus and concrete content was estimated using food grade hexane as solvent. Soluble extract was then drained off into a pre weighed $100 \mathrm{ml}$ beaker $\left(\mathrm{W}_{1}\right)$. The extract was then evaporated on a steam bath and heated for 30 minutes in an oven at $60^{\circ} \mathrm{C}$, cooled and weighed $\left(\mathrm{W}_{2}\right)$. The concrete content was calculated using the following formula and expressed in per cent.

Concrete content $(\%)=\frac{\mathrm{W}_{2}-\mathrm{W}_{1}}{\text {---------- }} \mathrm{x} 100$

\section{Volatile compound analysis using GC/MS analysis}

The volatile oil from Jasminum auriculatum flowers was dissolved in hexane and directly injected into the injection port of gas chromatograph (Agilent Technologies 7890A GC system) coupled with a mass spectrometer (Agilent Technologies 5975C inert XL EI/CI MSD with Triple-Axis Detector).

The GC was operated on an Agilent J\&W GC column HP5 column (30 m x $0.32 \mathrm{~mm}$, id. with $0.52 \mu \mathrm{m}$ film thickness) and helium was used as the carrier gas. The temperature program was started with an initial temperature of $150^{\circ} \mathrm{C}$ and held for $4 \mathrm{~min}$ at this temperature, then heated up to $170^{\circ} \mathrm{C}$ with a heating rate of $0.8^{\circ} \mathrm{C} / \mathrm{min}$ and held for $1 \mathrm{~min}$, heated up to $220^{\circ} \mathrm{C}$ with a heating rate of $3.0^{\circ} \mathrm{C} / \mathrm{min}$ and held for $1 \mathrm{~min}$, heated up to $240^{\circ} \mathrm{C}$ with a heating rate of $1.0^{\circ} \mathrm{C} / \mathrm{min}$ and held for $1 \mathrm{~min}$ and heated up to $250^{\circ} \mathrm{C}$ with a heating rate of $5.0^{\circ} \mathrm{C} / \mathrm{min}$ and held for $5 \mathrm{~min}$ at a flow rate of $0.7 \mathrm{~mL} / \mathrm{min}$. The obtained mass spectra were preliminarily interpreted by comparing with those of Enhance Chemstation Version D00.00.38 (Agilent 
Technologies), the Mass Spectral Search Library of the National Institute of Standards and Technology (NIST, Gaithersburg, USA).

\section{Results and Discussion}

The concrete of three varieties of Jasminum auriculatum viz., CO-1 mullai, CO-2 mullai and Parimullai was prepared by solvent extraction. The percentage of the concrete in those varieties was ranged from 0.28 to $0.36 \%$ per cent (Table 1). The highest recovery of 0.36 per cent was observed in $\mathrm{CO}-2$ mullai while the variety $\mathrm{CO}-1$ mullai recorded 0.28 percent and Parimullai recorded 0.29 percent. The chromatogram generated by gas chromatography shows the composition of the volatile oils from Jasminum auriculatum varieties viz., CO-1 mullai, CO-2 mullai and Parimullai (Fig. 1).

GC/MS analysis of CO-1 mullai concrete resulted in the identification of major compounds as 17-Pentatriacontene; 22Tricosenoic acid; 1-Hexacosene; Oleic acid, 3-(octadecyloxy) propyl ester; Tetrapentacontane, 1,54-dibromo were (Table 2, Fig 2). Whereas, 2,5-Octadecadiynoic acid, methyl ester; Acetic acid, 7-hydroxy1,3,4,5,6,7-hexahydro-2H-naphthalen-4 aylmethyl ester; Methyl 2,4-tridecadiynoate; 4,7-Octadecadiynoic acid, methyl ester; Bicyclo[3.1.1]hept-3-ene-spiro-2,4'-(1',3'dioxane), 7,7-dimethy were present as minor compounds.

Fig.1 The GC chromatograms of volatile compounds of Jasminum auriculatum varieties (CO-1 mullai, CO-2 mullai and parimullai)
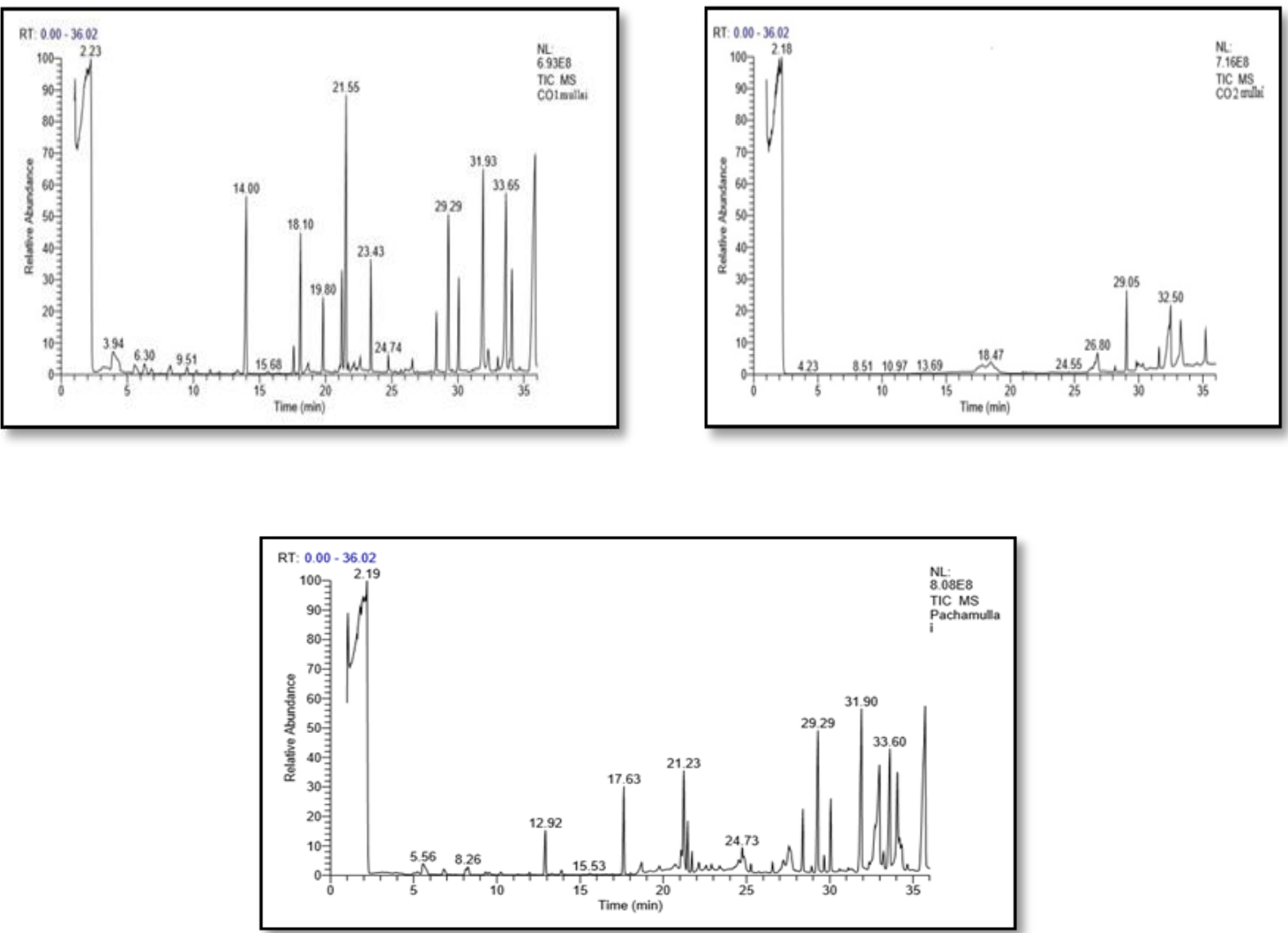
Fig.2 Chemical structure of volatile compounds of Jasminum auriculatum variety CO-1 mullai
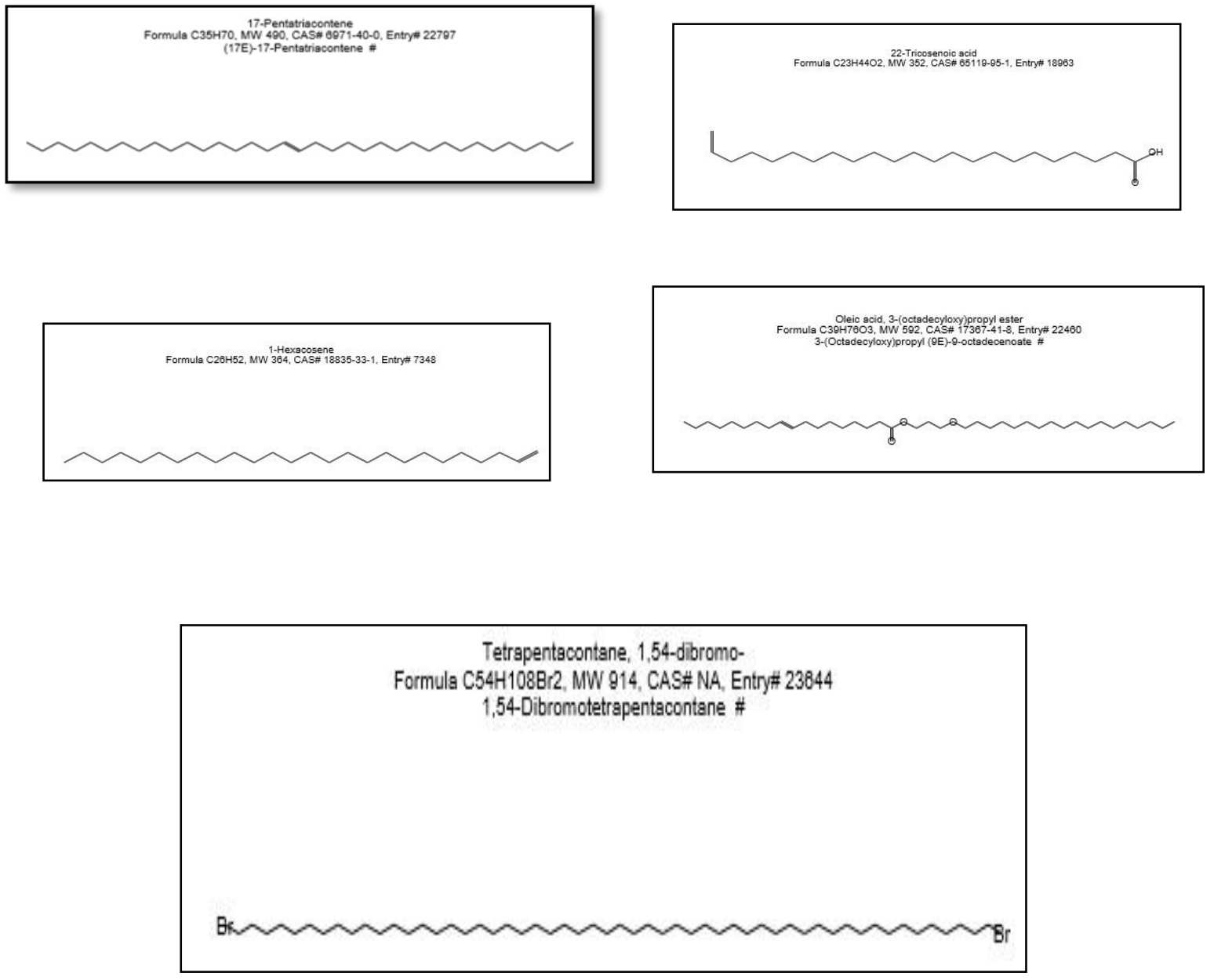

Fig.3 Chemical structure of volatile compounds of Jasminum auriculatum variety CO-2 mullai

Cholest-22-ene-21-ol, 3,5-dehydro-6-methoxy-, pivalate Formula C33H54O3, MW 498, CAS\# NA, Entry\# 22762


Fig.4 Chemical structure of volatile compounds of Jasminum auriculatum variety Parimullai
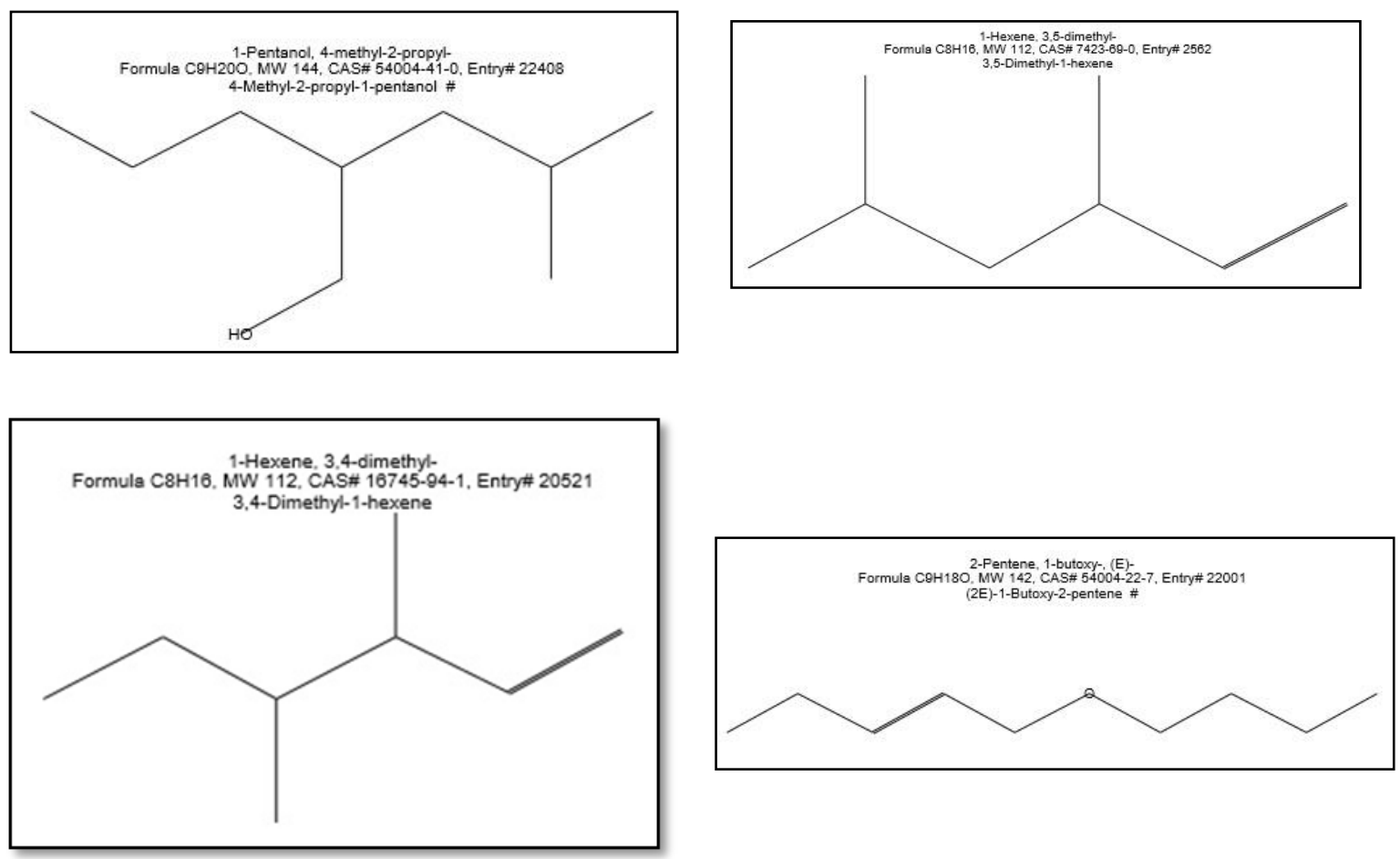


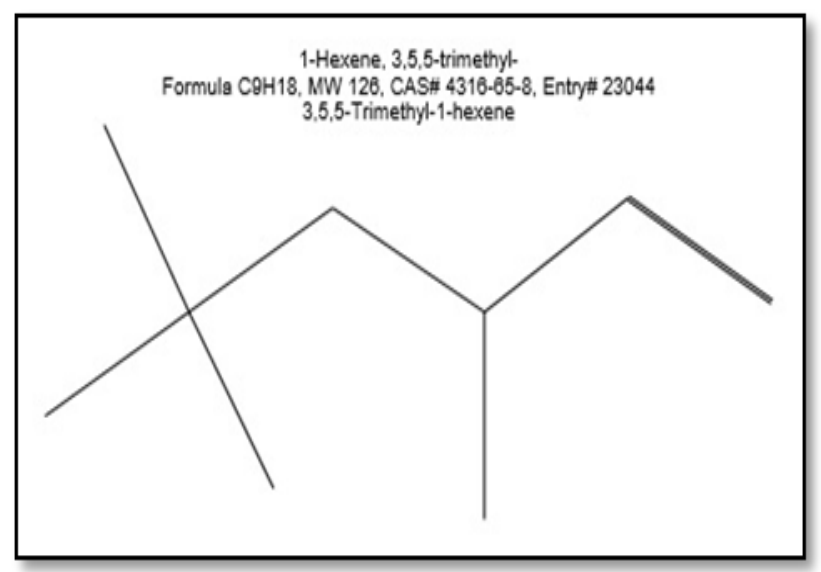

Table.1 Concrete recovery from Jasminum auriculatum flowers

\begin{tabular}{|l|l|l|}
\hline S.No. & Varieties & Concrete recovery $(\%)$ \\
\hline 1. & CO-1 mullai & 0.28 \\
\hline 2. & CO-2 mullai & 0.36 \\
\hline 3. & Parimullai & 0.29 \\
\hline SE(D) & 0.02 \\
\hline CD $(0.5)$ & 0.05 \\
\hline
\end{tabular}

Table.2 Chemical composition of J. auriculatum variety CO-1 mullai concrete

\begin{tabular}{|l|l|l|l|c|}
\hline S.No & RT & Compounds available & $\begin{array}{l}\text { Molecular } \\
\text { weight }\end{array}$ & $\begin{array}{l}\text { \% Retention } \\
\text { area }\end{array}$ \\
\hline 1. & 2.17 & 17-Pentatriacontene & 490 & 34.49 \\
\hline 2. & 2.17 & 22-Tricosenoic acid & 352 & 34.49 \\
\hline 3. & 2.17 & 1-Hexacosene & 364 & 34.49 \\
\hline 4. & 2.17 & $\begin{array}{l}\text { Oleic acid, 3-(octadecyloxy) } \\
\text { propyl ester }\end{array}$ & 592 & 34.49 \\
\hline 5. & 2.17 & Tetrapentacontane, 1, 54-dibromo & 914 & 34.49 \\
\hline
\end{tabular}

Table.3 Chemical composition of J. auriculatum variety CO-2 mullai concrete

\begin{tabular}{|l|l|l|c|c|}
\hline S.No & RT & Compounds available & $\begin{array}{c}\text { Molecular } \\
\text { weight }\end{array}$ & $\begin{array}{c}\text { \% Retention } \\
\text { area }\end{array}$ \\
\hline 1. & 2.14 & 17-Pentatriacontene & 490 & 34.49 \\
\hline 2. & 2.14 & $\begin{array}{l}\text { Octadecane,3-ethyl-5-(2- } \\
\text { ethylbutyl) }\end{array}$ & 366 & 34.49 \\
\hline 3. & 2.14 & $\begin{array}{l}\text { Cholest-22-ene-21-ol,3,5- } \\
\text { dehydro-6-methoxy-,pivalate }\end{array}$ & 498 & 34.49 \\
\hline 4. & 2.14 & $\begin{array}{l}\text { Oleic acid, 3-(octadecyloxy) } \\
\text { propyl ester }\end{array}$ & 592 & 34.49 \\
\hline 5. & 2.14 & Tetrapentacontane,1,54-dibromo & 914 & 34.49 \\
\hline
\end{tabular}


Table.4 Chemical composition of J. auriculatum variety Parimullai concrete

\begin{tabular}{|l|l|l|c|c|}
\hline S.No & RT & Compounds available & Molecular weight & \% Retention area \\
\hline 1. & 2.10 & 1-Pentanol, 4-methyl-2-propyl- & 144 & 45.12 \\
\hline 2. & 2.10 & 1-Hexene,3,5-dimethyl- & 112 & 37.30 \\
\hline 3. & 2.10 & 1-Hexene,3,4-dimethyl- & 112 & 37.30 \\
\hline 4. & 2.10 & 2-Pentene,1-butoxy & 142 & 37.30 \\
\hline 5. & 2.10 & 1-Hexene,3,5,5-trimethyl & 126 & 37.30 \\
\hline
\end{tabular}

The results of GC/MS analysis of CO-2 mullai concrete opined that 17-Pentatriacontene; Octadecane,3-ethyl-5-(2-ethylbutyl); Cholest22-ene-21-ol,3,5-dehydro-6-methoxy-,pivalate; Oleic acid,3-(octadecyloxy) propyl ester; Tetrapentacontane,1,54-dibromo were contributed as major constitutes (Table 3, Fig 3). While, 11,13-Dihydroxy-tetradec-5-ynoic acid, methyl ester; 6,9,12,15-Docosatetraenoic acid, methyl ester; cis-5,8,11,14,17Eicosapentaenoic acid; 2-[4-methyl-6-(2,6,6trimethylcyclohex-1-enyl)hexa-1,3,5trienyl]cyclohex-1-en-1 carboxaldehyde; Formic acid, 3,7,11-trimethyl-1,6,10dodecatrien- ester were present as minors or traces.

In Parimullai concrete, GC/MS analysis resulted with 11-Pentanol,4-methyl-2-propyl; 1Hexene,3,5-dimethyl-; 1-Hexene,3,4-dimethyl-; 2-Pentene,1-butoxy; 1-Hexene,3,5,5-trimethyl were expressed as major compounds (Table 4, Fig 4). Whereas, 1,4-Methanoazulen-7-ol; decahydro-1,5,5,8a-tetramethyl-; 2,2,6Trimethyl-1-(3-methylbuta-1,3-dienyl)-7-ox abicyclo heptan-3-ol, Isoaromadendrene epoxide; Cyclopropa(d)naphthalene-3-one, octahydro-2,4a,8-8-tetramethyl, oxime; 7Hydroxy-6,9a-dimethyl-3-methylenedecahydro-azuleno(4,5-b)furan-2,9-dione were present as minors or traces.

\section{References}

Arumugam, T., Jawaharlal, M., Vijayakumar, M. and Bhattacharjee, S.K. 2002. Jasmine. AICRP on Floriculture. Technical bulletin No.17.

ASTA 1960. Official analytical methods of the American Spice Trade Association, New York, pp. 41-42.

Bramer S. E. V.1998. An Introduction to Mass Spectrometry. Widener University. Department of Chemistry. pp.26.

Green, P. and Miller, D. 2009. The genus Jasminum in cultivation. Kew Publishing, Royal Botanic Gardens, Kew.

Kulkarmi, P.H. and Ansari, S. 2004. The Ayurvedic Plants. Indian Medical Science, 132:9.

Rimando, T. J. 2003. Sampaguita production. In: Ornamental Horticulture: A little giant in the tropics. SEAMEO SEARCA and UPLB, College, Los Banos, Laguna, Philippines, pp: 333.

Sharma, P.C., Yelne, M.B. and Dennis, T.J. 2005. Data base on Medicinal Plants Used in Ayurveda. CCRAS, New Delhi, 332-345.

Younis, A., Riaz, A., Khan, M. A., Khan, A. A. and Pervez, M. A. 2008. Extraction and identification of chemical constituents of the essential oil of Rosa species. Acta Hort., 766: 485-492.

\section{How to cite this article:}

Ranchana, P., M. Ganga, M. Jawaharlal and Kannan, M. 2017. Investigation of Volatile Compounds from the Concrete of Jasminum auriculatum Flowers. Int.J.Curr.Microbiol.App.Sci. 6(11): 1525-1531. doi: https://doi.org/10.20546/ijcmas.2017.611.180 